\title{
SISTEM INFORMASI MANAJEMEN WARUNG INTERNET (WARNET) BERBASIS GOOGLE MAPS API (STUDI KASUS : KABUPATEN KARANGANYAR)
}

\author{
Khilliyatul Lubbi \\ Fakultas MIPA, Informatika \\ Universitas Negeri Sebelas Maret \\ Email: khiliyatul.lubbi@ student.uns.ac.id \\ Abdul Aziz \\ Fakultas MIPA, Informatika \\ Universitas Negeri Sebelas Maret \\ Email : aaziz@staff.uns.ac.id
}

\begin{abstract}
ABSTRAK
Abstrak - Dinas Perhubungan Komunikasi dan Informatika Karanganyar (Dishubkominfo) sebagai salah satu dinas yang membantu urusan pemerintah memiliki banyak tugas, salah satunya adalah mengelola perizinan pendirian warnet. Dalam mengelola perizinan pendirian warnet tersebut mulai dari pengajuan rekomendasi perizinan pendirian warnet hingga keluar terbitan rekomendasi izin pendirian, Dishubkominfo masih menggunakan cara manual, sehingga semua data warnet pun tersimpan dalam Microsoft Excel, Microsoft Word, atau bahkan print out. Pengelolaan tugas dengan cara seperti itu menyebabkan ketidakefektifan dan kesulitan pada saat pengarsipan.

Dengan adanya permasalahan tersebut, maka dibangun sebuah sistem untuk mengelola perizinan pendirian warnet di Kabupaten Karanganyar yang dilengkapi peta persebaran lokasi warnet dengan menggunakan Google Maps API. Dengan adanya sistem ini, pemohon hanya perlu datang membawa berkas ke Dishubkominfo ketika berkasnya sudah dipastikan lengkap dan benar oleh pihak Dishubkominfo melalui sistem. Selain itu, Sistem dapat memudahkan tugas mulai dari pengajuan rekomendasi warnet oleh pemohon hingga keluar terbitan rekomendasi izin pendirian dari Dishubkominfo.

Sistem yang dibuat diuji dengan menggunakan dua metode, yaitu metode blackbox dan menggunakan tools GT Metrix. Dengan menggunakan metode blackbox, sistem memiliki tingkat kesuksesan (fungsional yang diterima) dengan kisaran 98\%, dan tidak suskes sekitar $2 \%$. Sedangkan pengujian menggunakan GT Metrix menunjukkan rata-rata performa Page Speed Score sekitar 40\% dan performa YSlow sekitar 78\%.
\end{abstract}

Kata kunci: warung internet, google maps API, GT Metrix, Page Speed Score, YSlow.

\begin{abstract}
Department of Communication and Information Karanganyar (Dishubkominfo) as one of the agencies that help the government affairs have many tasks, one of which is to manage the licensing of establishment cafe. In managing the cafe licensing establishments ranging from the filing of the cafe establishment licensing recommendations to come out of issue on establishment licenses, Dishubkominfo still use manual way, so that all the data the cafe were stored in Microsoft Excel, Microsoft Word, or even print out. Management of the job as it causes inefficiencies and difficulties at the time of filing.

Given these problems, then built a system to manage permissions establishments cafe in Karanganyar equipped cafe spread map location using the Google Maps API. With this system, applicants only need to be brought to Dishubkominfo file when the file has been ascertained completely and correctly by the Dishubkominfo through the system. In addition, the system can facilitate the task of starting from the submission of recommendations by the applicant until the exit cafe issue recommendation permits the establishment of Dishubkominfo.
\end{abstract}


The system created tested using two methods, the methods and use tools blackbox GT Metrix. By using blackbox, the system has a success rate (functional received) with a range of $98 \%$, and not suskes about 2\%. While testing using GT Metrix shows the average performance of the Page Speed Score of about $40 \%$ and about $78 \%$ YSlow performance.

Keywords: internet cafes, google maps API, GT Metrix, Page Speed Score, YSlow.

\section{Pendahuluan}

Kebutuhan teknologi informasi semakin menjadi hal yang sangat penting bagi manusia.Teknologi informasi dapat digunakan untuk memperoleh informasi ataupun interaksi antar manusia.Pertukaran informasi dan intreaksi yang terjadi di dunia menadi lebih cepat sejak internet diberdayagunakan.

Saat ini banyak instansi yang memanfaatkan internet dalam proses kegiatan kerja, baik hanya sekadar menyampaikan informasi atau untuk membantu aktivitas yang terdapat dalam instansi tersebut.

Dinas Perhubungan Komunikasi dan Informatika Karanganyar merupakan salah satu instansi yang memanfaatkan internet dalam interaksi kepada masyarakat.Dinas Perhubungan Komunikasi dan Informatika Karanganyar terdiri dari 2 bidang, yaitu bidang Perhubungan dan bidang Komunikasi dan Informatika (Kominfo).Bidang Kominfo membawahi seksi Informasi dan Pemberitaan, Seksi Komunikasi dan Informatika seksi komunikasi sebagai salah satu seksi dalam bidang Kominfo memiliki tugas untuk mengelola perizinan pendirian warnet di Kabupaten Karanganyar. Tetapi dalam pengelolaan yang dilakukan masih menggunakan sistem manual. Padahal jika dilakukan secara manual, masyarakat yang akan melakukan permohonan perizinan pendirian warnet dapat mengumpulkan berkas secara fisik, dengan kata lain dapat datang ke Dinas Perhubungan Komunikasi dan Informatika berulang kali ketika berkas belum lengkap atau masih salah. Selain itu, pendataan data warnet oleh pegawai masih dilakukan secara manual, sehingga perlu dibuat sistem yang dapat mengelola perizinan pendirian warnet itu sendiri yang dilengkapi dengan persebaran lokasi warnet yang terdapat di Kabupaten Karanganyar.

Pada penelitian sebelumnya [5], Google Maps API dimanfaatkan pada pembangunan sistem informasi manajemen bantuan logistic pasca bencana berbasis mobile web.

Berdasarkan hal tersebut, dibangun sebuah sistem yang dapat memanajemen warnet di Kabupaten Karanganyar yang dilengkapi dengan peta persebaran lokasi warnet. Dengan begitu, masyarakat yang akan melakukan permohonan perizinan warnet dapat mengumpulkan berkas secara fisik satu kali saja saat berkas sudah lengkap dan benar. Selain itu, pegawai dapat melakukan pendataan warnet yang ada di Kabupaten Karanganyar dengan lebih mudah. Tetapi laporan ini hanya fokus pada perizinan pendirian warnet di Kabupaten Karanganyar

Melalui pengelolaan perizinan pendirian warnet di Karanganyar menggunakan sistem informasi ini akan memudahkan pegawai maupun masyarakat dalam melakukan interaksi, pertemuan secara fisik dapat dikurangi karena masyarakat baru perlu mengumpulkan berkas perizinan pendirian ketika file pengajuan yang diajukan sudah lengkap dan benar. Diharapkan dengan adanya sistem informasi peirzinan pendirian warnet ini dapat lebih menunjang dan mengefektifkan proses perizinan pendirian warnet.

\section{Metodologi}

\section{a. Metode Pengumpulan Data}

Metode pengumpulan data merupakan cara yang digunakan untuk mengumpulkan data-data yang diperlukan untuk memenuhi kebutuhan sistem. Data-data yang sudah terkumpul disatukan sehingga didapatkan sebuah informasi yang bermanfaat.

Sumber data untuk pembangunan sistem ini terdapat 2, yaitu :

1) Data Primer

Data primer merupakan data yang didapatkan langsung dari pemberi informasi di Dinas Perhubungan, Komunikasi, dan Informatika Karanganyar. Data primer yang digunakan dalam penelitian ini 
didapatkan melalui metode wawancara. Metode wawancara merupakan teknik pengumpulan data yang dilakukan dengan tatap muka dan tanya jawab langsung antara pengumpul data terhadap nara sumber.

Selama proses penelitian, dilakukan wawancara dengan pihak terkait yaitu pegawai Seksi Komunikasi bidang Kominfo di Dinas Perhubungan, Komunikasi, dan Informatika Karanganyar untuk mendapatkan informasi yang dibutuhkan dalam proses pembangunan sistem.

2) Data Sekunder

Data sekunder adalah data yang didapat tidak secara langsung dari pemberi informasi. Data sekunder untuk pembangunan sistem ini dilakukan dengan cara studi literatur yaitu mencari informasi dari buku, jurnal, internet dan sebagainya yang terkait dengan proses pembangunan sistem.

\section{b. Metode Pengembangan Sistem}

Metode pengembangan sistem yang digunakan meliputi : Perencanaan, Desain, Coding, dan Testing.

1) Perencanaan

Tahap perencanaan merupakan tahap awal pada proses pengembangan sistem. Dalam tahap ini dilakukan analisis kebutuhan yang nantinya akan dibutuhkan dalam pengembahan sistem.

2) Desain

Setelah tahap perencanaan selesai dilakukan, tahap selanjutnya adalah desain. Pada tahap ini dilakukan proses mendesain beberapa hal, sebagai berikut :

a. Perancangan Proses

b. Perancangan Data

3) Coding (Implementasi)

Setelah desain sistem selesai dilakukan, langkah selanjutnya adalah coding, yaitu menerjemahkan hasil desain ke dalam bentuk mesin yang dapat dibaca oleh perangkat keras.

4) Pengujian

Pengujian yang dilakukan berfungsi untuk mengecek apakah ada error dalam sistem. Jika masih terdapat error, maka kode diperbaiki kembali.

\section{Hasil dan Pembahasan}

\section{A. Perencanaan}

1) Deskripsi Umum Sistem

Sistem yang dibuat adalah sistem untuk mengelola perizinan warnet di Kabupaten Karanganyar. Sistem ini dibuat untuk memudahkan Pegawai Dinas Perhubungan,Komunikasi dan Informatika Karanganyar khususnya Seksi Komunikasi di bawah bidang Kominfo maupun masyarakat yang akan mengajukan permohonan atau pencabutan izin pendirian warnet. Dengan adanya sistem ini, Kepala Dinas Perhubungan Komunikasi dan Informatika Kabupaten Karanganyar akan dimudahkan dalam melihat pelaporan warnet itu sendiri. Sistem ini memiliki 4 fungsi utama, yaitu :

a. Pengelolaan Perekomendasian Warnet

Pengelolaan perekomendasian warnet ini meliputi pengelolaan berkas persyaratan pengajuan rekomendasi, pengelolaan pengajuan rekomendasi warnet, pengelolaan hasil survei, pengelolaan data warnet, dan pengelolaan terbitan rekomendasi.Pada pengelolaan perekomendasian warnet ini terdapat beberapa fungsi, yaitu mengunggah berkas persyaratan dan menghapus berkas persyaratan oleh pegawai, menampilkan berkas persyaratan dan mengunduh berkas persyaratan yang dapat dilakukan oleh pegawai, pemohon, dan pengunjung. Kemudian terdapat fungsi mengajukan rekomendasi warnet oleh pemohon, menampilkan daftar ajuan rekomendasi, mengunduh berkas ajuan rekomendasi, memberi status ajuan dan mengubah status ajuan oleh pegawai, menampilkan daftar ajuan rekomendasi milik sendiri dan melihat status ajuan oleh pemohon, memberi hasil survei, mengubah hasil survei, menampilkan hasil survei, menambah data warnet, mengubah data warnet, menampilkan data warnet, menambah terbitan rekomendasi, mengubah terbitan rekomendasi, menampilkan terbitan rekomendasi dan mencetak terbitan rekomendasi oleh pegawai

b. Pengelolaan Pencabutan Warnet

Pengelolaan pencabutan izin warnet ini meliputi mengajukan pencabutan warnet oleh pengunjung dan melaporkan pencabutan izin warnet oleh pegawai. 


\section{c. Pengelolaan Pengguna}

Pengelolaan pengguna ini meliputi menambah pengguna dan mengubah pengguna.Keduanya hanya dapat dilakukan oleh pegawai.

d. Pelaporan Warnet

Pelaporan warnet ini meliputi mencari pelaporan warnet dan mencetak pelaporan warnet yang dapat dilakukan oleh kepala dan pegawai.Kemudian meliputi fungsi menampilkan peta yang dapat dilakukan oleh Kepala, pegawai, pemohon, dan pengunjung.

2) Identifikasi Pengguna

Dalam sistem ini terdapat empat aktor atau pengguna, yaitu : kepala, pegawai, pemohon, dan pengunjung. Di bawah ini merupakan identifikasi dari pengguna tersebut :

a. Kepala, sebagai pengguna yang dapat melihat pelaporan warnet. Kepala dapat mencari pelaporan warnet, mencetak pelaporan warnet, dan menampilkan peta.

b. Pegawai, sebagai pengguna yang berperan dalam mengunggah berkas persyaratan pengajuan rekomendasi, mengunduh berkas persyaratan, menghapus berkas persyaratan, mengunduh berkas ajuan rekomendasi, memberi status ajuan dan mengubah status ajuan, memberi hasil survei, mengubah hasil survei, menambah data warnet, mengubah data warnet, menambah terbitan rekomendasi, mengubah terbitan rekomendasi, dan mencetak terbitan rekomendasi. Pegawai juga dapat menampilkan peta

c. Pemohon, sebagai pengguna yang memiliki hak untuk mengunduh berkas persyaratan, mengajukan rekomendasi warnet, melihat status ajuan, serta menampilkan peta.

d. Pengunjung, sebagai pengguna yang dapat menampilkan peta, mengunduh berkas persyaratan, melihat daftar warnet yang berstatus aktif dan tercabut, dan mengajukan pencabutan warnet. Pengunjung merupakan aktor paling umum, artinya kepala, pegawai, dan pemohon merupakan pengunjung sehingga dapat melakukan fungsi yang dilakukan oleh pengunjung.

3) Kebutuhan Fungsional

Kebutuhan Fungsional Sistem yang dibuat ditunjukkan pada Tabel 1.

Tabel 1. Kebutuhan Fungsional

\begin{tabular}{|c|c|c|}
\hline Functional & Aktor & Deskripsi \\
\hline $\begin{array}{l}\text { Mengunggah berkas } \\
\text { persyaratan }\end{array}$ & Pegawai & $\begin{array}{l}\text { Mengunggah berkas persyaratan yang digunakan dalam pengajuan } \\
\text { rekomendasi warnet }\end{array}$ \\
\hline $\begin{array}{l}\text { Mengunduh berkas } \\
\text { persyaratan }\end{array}$ & $\begin{array}{l}\text { Pegawai, Pemohon, } \\
\text { Pengunjung }\end{array}$ & $\begin{array}{l}\text { Mengunduh berkas persyaratan yang digunakan dalam pengajuan } \\
\text { rekomendasi warnet yang diunggah oleh pegawai }\end{array}$ \\
\hline $\begin{array}{l}\text { Menghapus berkas } \\
\text { persyaratan }\end{array}$ & Pegawai & $\begin{array}{l}\text { Menghapus berkas persyaratan dengan mengkopi ke tabel lain data yang } \\
\text { akan dihapus. }\end{array}$ \\
\hline $\begin{array}{l}\text { Mengajukan } \\
\text { rekomendasi warnet }\end{array}$ & Pemohon & Mengunggah file pengajuan rekomendasi warnet \\
\hline $\begin{array}{l}\text { Mengunduh berkas } \\
\text { ajuan rekomendasi }\end{array}$ & Pegawai & Mengunduh file ajuan rekomendasi warnet yang diajukan oleh pemohon \\
\hline Memberi status ajuan & Pegawai & $\begin{array}{l}\text { Memberi keterangan pada file ajuan rekomendasi warnet yang diajukan } \\
\text { oleh pemohon, dikoreksi apakah file sudah lengkap atau belum. }\end{array}$ \\
\hline Mengubah status ajuan & Pegawai & Mengedit keterangan pada file ajuan yang telah diberikan \\
\hline Melihat status ajuan & Pemohon & $\begin{array}{l}\text { Menampilkan status ajuan rekomendasi yang telah diajukan agar } \\
\text { pemohon dapat mengetahui apakah file ajuannya sudah lengkap atau } \\
\text { masih belum lengkap }\end{array}$ \\
\hline Menambah hasil survei & Pegawai & $\begin{array}{l}\text { Menambah hasil survei pada file ajuan yang sudah lengkap, data yang } \\
\text { dimasukkan adalah data hasil survei ke lapangan. }\end{array}$ \\
\hline Mengubah hasil survei & Pegawai & Mengedit hasil survei yang telah ditambahkan. \\
\hline Menambah data warnet & Pegawai & $\begin{array}{l}\text { Menambahkan data warnet berdasarkan hasil survei. Data yang } \\
\text { ditambahkan adalah data yang belum memiliki nomor rekomendasi. } \\
\text { Menambah data warnet sekaligus memberi status aktif pada warnet yang } \\
\text { ditambahkan. }\end{array}$ \\
\hline Mengubah data warnet & Pegawai & Mengedit data warnet yang telah ditambahkan \\
\hline
\end{tabular}




\begin{tabular}{|c|c|c|}
\hline $\begin{array}{l}\text { Menambah terbitan } \\
\text { rekomendasi }\end{array}$ & Pegawai & Memberi nomor rekomendasi pada data warnet yang telah ditambahkan \\
\hline $\begin{array}{l}\text { Mengubah terbitan } \\
\text { rekomendasi }\end{array}$ & Pegawai & Mengedit data warnet yang telah memiliki nomor rekomendasi \\
\hline $\begin{array}{l}\text { Mencetak terbitan } \\
\text { rekomendasi }\end{array}$ & Pegawai & Mencetak daftar warnet yang telah memiliki nomor rekomendasi \\
\hline $\begin{array}{l}\text { Mengajukan } \\
\text { pencabutan izin warnet }\end{array}$ & Pengunjung & $\begin{array}{l}\text { Mengadukan keluhan atas gangguan yang terjadi akibat beridirinya suatu } \\
\text { warnet }\end{array}$ \\
\hline $\begin{array}{l}\text { Melaporkan } \\
\text { pencabutan izin warnet }\end{array}$ & $\begin{array}{l}\text { Pegawai, } \\
\text { Pengunjung }\end{array}$ & $\begin{array}{l}\text { Mengubah status warnet yang semula aktif menjadi tercabut berdasarkan } \\
\text { aduan dari pengunjung dan aduan tersebut telah terbukti. }\end{array}$ \\
\hline Menambah Pengguna & Pegawai & Menambah data pengguna, meliputi Kepala dan Pegawai \\
\hline Mengubah Pengguna & Pegawai & Mengubah Data Pengguna \\
\hline $\begin{array}{l}\text { Mencari pelaporan } \\
\text { warnet }\end{array}$ & Kepala, Pegawai & Mencari daftar warnet berdasarkan kategori yang telah disediakan \\
\hline $\begin{array}{l}\text { Mencetak pelaporan } \\
\text { warnet }\end{array}$ & Kepala, Pegawai & Mencetak daftar warnet hasil pencarian \\
\hline Menampilkan peta & $\begin{array}{l}\text { Kepala, Pegawai, } \\
\text { Pemohon, } \\
\text { Pengunjung }\end{array}$ & Menampilkan peta lokasi warnet yang masih memiliki status aktif \\
\hline
\end{tabular}

\section{4) Kebutuhan Non-Fungsional}

Di bawah ini merupakan functional requirement pada sistem yang telah dibuat :

a. Mudah digunakan

b. Dapat digunakan untuk upload file dengan ekstensi .doc, .docx, .xls, .pdf, .rar, .zip.

B. Desain

1) Perancangan Proses

a. Flowchart

Flowchart dibuat sejumlah fungsional yang ada dalam sistem manajemen warnet.

b. Context Diagram (CD)

Di bawah ini merupakan Context Diagram dari sistem informasi manajemen warnet. Dari diagram berikit, dapat diketahui proses yang berjalan. Dalam sistem ini terdapat 4 entitas (aktor) yaitu Kepala, Pegawai, Pemohon, dan Pengunjung.

Context Diagram Sistem dapat dilihat pada Gambar 1

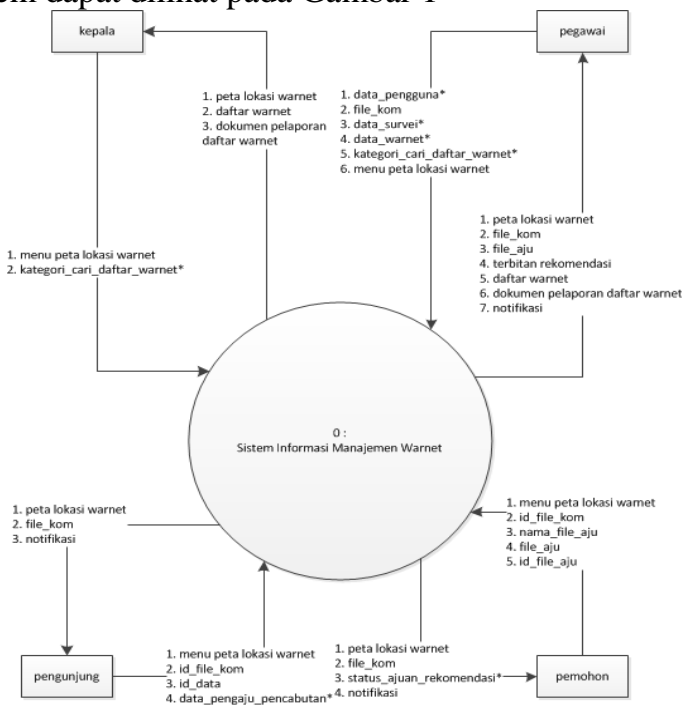

Gambar 1. Context Diagram 
Kamus data dari Context Diagram pada sistem ini ditunjukkan pada Tabel 2

Tabel 2. Kamus Data Context Diagram

\begin{tabular}{ll}
\hline $\begin{array}{l}\text { kategori_cari_daftar_ } \\
\text { warnet* }\end{array}$ & Kategori kecamatan, kategori no_rekomendasi, kategori status \\
\hline data_warnet* & $\begin{array}{l}\text { id_data, nama, alamat, lat, lng, tipe, } \\
\text { kecamatan, nama_pemilik, no_telp, tgl, bln, thn, no_rekomendasi, status, sid }\end{array}$ \\
data_pengguna* & $\begin{array}{l}\text { nomor_identitas, nama_lengkap, penggunaname, password, } \\
\text { konfirmasi_password, email, no_telp, level, uid }\end{array}$ \\
$\begin{array}{l}\text { no_identitas, nama_lengkap, email, } \\
\text { no_telp, alasan, } \\
\text { utan* } \\
\text { data_survei* }\end{array}$ & $\begin{array}{l}\text { sid, nama, alamat, lat, lng, tipe, kecamatan, nama_pemilik, no_telp, } \\
\text { tanggal_survei,, hasil_survei }\end{array}$ \\
$\begin{array}{l}\text { id_corrected, id_file_aju, keterangan } \\
\text { status_ajuan_rekomen } \\
\text { dasi* }\end{array}$ &
\end{tabular}

2) Perancangan Data

a. Entity Relationship Diagram \& Schema Diagram

ERD pada sistem informasi manajemen warnet ini mempunyai 9 entitas. Kesembilan entitas tersebut adalah Penggunas, Uploadedkom, Uploadedkom2, Uploaded_file, Corrected, Survei, Data_Warnet, Aju_pembatalan, dan Message.Di bawah ini merupakan ERD dari sistem informasi manajemen warnet di Kabupaten Karanganyar.

Berikut merupakan diagram skema yang dibuat dalam membangun sistem informasi manajemen warnet di Karanganyar. Tabel Message merupakan tabel yang tidak memiliki relasi karena memang tidak terhubung dengan tabel manapun.

Schema Diagram pada sistem ini ditunjukkan pada Gambar 2.

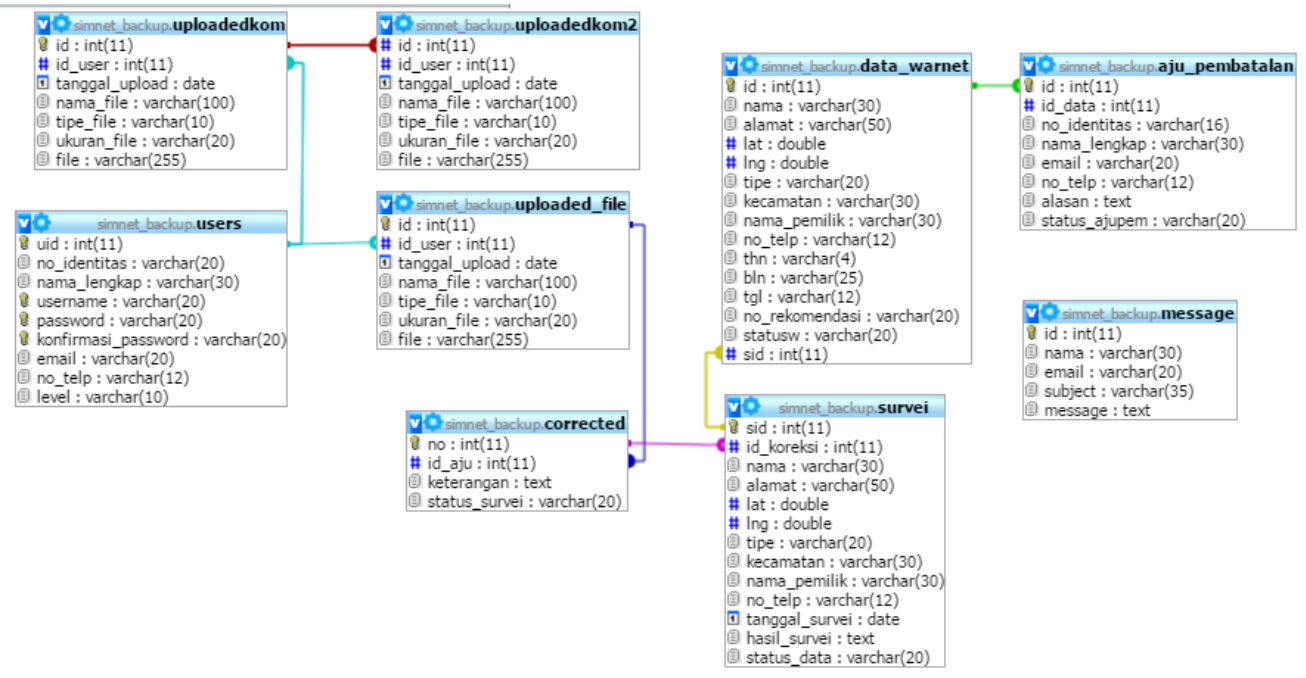

Gambar 2. Schema Diagram 
C. Coding (Implementasi)

Di bawah ini merupakan implementasi beberapa halaman sistem yang dibuat.

1) Interface Pengelolaan Perekomendasian Warnet

Implementasi Interface Pengelolaan Perekomendasian Warnet ditunjukkan pada Gambar 3

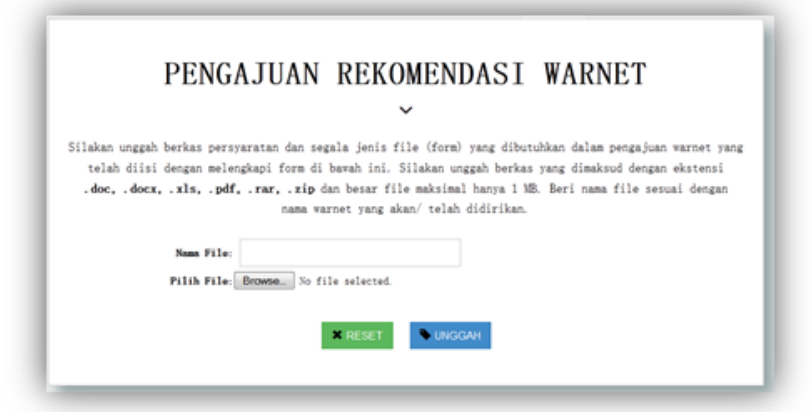

Gambar 3. Interface Pengelolaan Perekomendasian Warnet

2) Interface Pengelolaan Pencabutan Warnet

Implementasi Interface Pengelolaan Pencabutan Warnet ditunjukkan pada Gambar 4

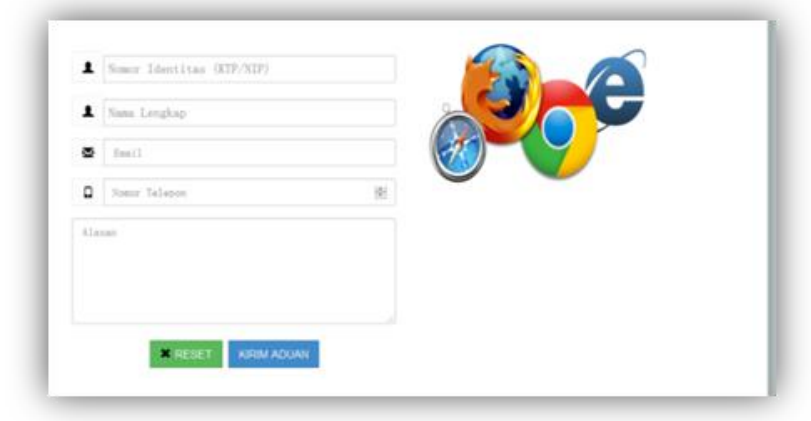

Gambar 4. Interface Pengelolaan Pencabutan Warnet

3) Interface Pengelolaan Pengguna

Implementasi Interface Pengelolaan Pengguna ditunjukkan pada Gambar 5

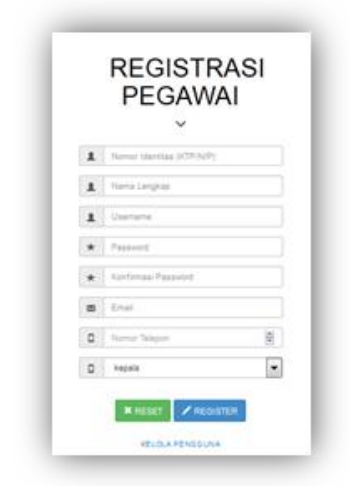

Gambar 5. Interface Pengelolaan Pengguna

4) Interface Pelaporan Warnet

Implementasi Interface Pelaporan Warnet ditunjukkan pada Gambar 6. 


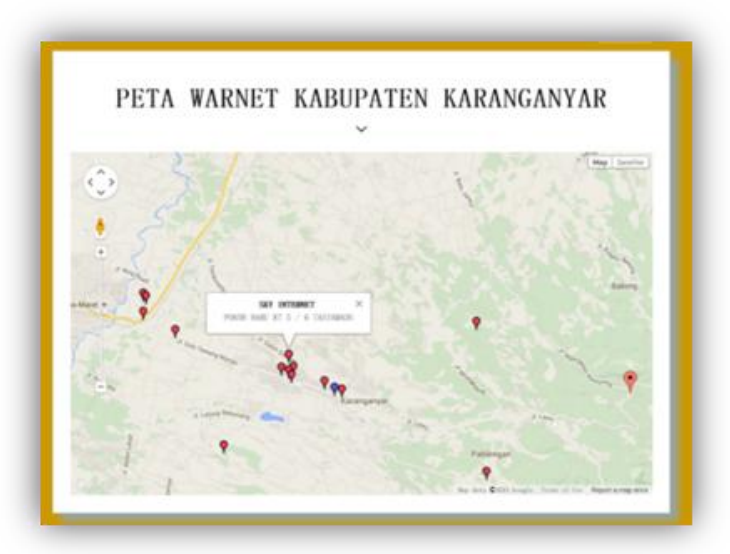

Gambar 6. Interface Pelaporan Warnet

\section{Pengujian}

Tahap setelah implementasi adalah pengujian sistem. Pengujian dilakukan untuk memeriksa dan mengetahui apakah sistem sudah berjalan sesuai dengan analisa dan desain yang dibuat.

Metode yang digunakan untuk melakukan pengujian terhadap sistem ini menggunakan pengujian manual dengan metode blackbox dan pengujian otomatis dengan menggunakan tools GT Metrix.

i. Pengujian Secara Manual

Hasil Pengujian Secara Manual menggunakan Metode Blackbox dapat dilihat pada Tabel 3

Tabel 3. HASIL PENGUJIAN MANUAL

\begin{tabular}{|c|c|c|c|}
\hline \multirow[t]{2}{*}{ Fungsional } & \multirow{2}{*}{$\begin{array}{c}\text { Jumlah } \\
\text { Kasus Uji }\end{array}$} & \multicolumn{2}{|c|}{ Simpulan } \\
\hline & & Diterima & $\begin{array}{c}\text { Tidak } \\
\text { Diterima }\end{array}$ \\
\hline Mengunggah Berkas Persyaratan & 3 & 3 & 0 \\
\hline Mengunduh Berkas Persyaratan & 1 & 1 & 0 \\
\hline Menghapus Berkas Persyaratan & 1 & 1 & 0 \\
\hline Mengajukan Rekomendasi Warnet & 5 & 5 & 0 \\
\hline Memberi Status Ajuan & 2 & 2 & 0 \\
\hline Mengubah Status Ajuan & 2 & 2 & 0 \\
\hline Melihat Status Ajuan & 2 & 1 & 1 \\
\hline Memberi Hasil Survei & 2 & 2 & 0 \\
\hline Mengedit Hasil Survei & 2 & 2 & 0 \\
\hline Menambah Data Warnet & 2 & 2 & 0 \\
\hline Mengubah Data Warnet & 2 & 2 & 0 \\
\hline Menambah Terbitan Rekomendasi & 2 & 2 & 0 \\
\hline Mencetak Terbitan Rekomendasi & 1 & 1 & 0 \\
\hline Mengubah Terbitan Rekomendasi & 2 & 2 & 0 \\
\hline Mengajukan Pencabutan Izin Warnet & 4 & 4 & 0 \\
\hline Melaporkan Warnet Tercabut & 1 & 1 & 0 \\
\hline Menambah Pengguna & 2 & 2 & 0 \\
\hline Mengubah Pengguna & 2 & 2 & 0 \\
\hline Mencari Pelaporan Warnet & 2 & 2 & 0 \\
\hline Mencetak Pelaporan Warnet & 2 & 2 & 0 \\
\hline Menampilkan Peta & 1 & 1 & 0 \\
\hline Jumlah & 43 & 42 & 1 \\
\hline
\end{tabular}

Dari 43 buah kasus pengujian terdapat satu buah defect (cacat) atau sekitar $2 \%$, sehingga fungsional yang sukses adalah sekitar $98 \%$.

ii. Pengujian Secara Otomatis

Pengujian otomatis yang digunakan untuk melakukan pengujian terhadap sistem ini menggunakan tools GT Metrix. Pengujian menggunakan GT Metrix digunakan untuk menguji performa sistem yang telah dibuat. Indikator yang digunakan dalam pengujian menggunakan GT 
Metrix adalah PageSpeed (Google) dan YSlow (Yahoo). Skor semakin tinggi menunjukkan performa halaman semakin baik.

Hasil Pengujian Secara Otomatis menggunakan Tools GT-Metrix dapat dilihat pada Tabel 4.

Tabel 4. HASIL PENGUJIAN OTOMATIS

\begin{tabular}{|c|c|c|c|c|c|}
\hline Fungsional & $\begin{array}{c}\text { Page } \\
\text { Speed } \\
\text { Score }\end{array}$ & $\begin{array}{l}\text { YSlow } \\
\text { Score }\end{array}$ & $\begin{array}{c}\text { Page } \\
\text { Load } \\
\text { Time } \\
\text { (s) }\end{array}$ & $\begin{array}{c}\text { Total } \\
\text { Page Size }\end{array}$ & $\begin{array}{c}\text { Re- } \\
\text { quests }\end{array}$ \\
\hline Mengunggah Berkas Persyaratan & $32 \%(\mathrm{~F})$ & $78 \%(C)$ & 2.8 & $425 \mathrm{~KB}$ & 17 \\
\hline Mengunduh Berkas Persyaratan & $35 \%(\mathrm{~F})$ & $77 \%(\mathrm{C})$ & 2.5 & $641 \mathrm{~KB}$ & 20 \\
\hline Menghapus Berkas Persyaratan & $57 \%(\mathrm{E})$ & $76 \%(C)$ & 6.2 & $2.79 \mathrm{MB}$ & 28 \\
\hline Mengajukan Rekomendasi Warnet & $34 \%(\mathrm{~F})$ & $77 \%(\mathrm{C})$ & 2.7 & $657 \mathrm{~KB}$ & 19 \\
\hline Memberi Status Ajuan & $32 \%(\mathrm{~F})$ & $77 \%(\mathrm{C})$ & 3.1 & $748 \mathrm{~KB}$ & 19 \\
\hline Mengubah Status Ajuan & $34 \%(\mathrm{~F})$ & $77 \%(\mathrm{C})$ & 4.8 & $748 \mathrm{~KB}$ & 20 \\
\hline Melihat Status Ajuan & $\begin{array}{c}100 \% \\
\text { (A) }\end{array}$ & $99 \%(\mathrm{C})$ & 31.6 & 534B & 1 \\
\hline Memberi Hasil Survei & $37 \%(\mathrm{~F})$ & $77 \%(\mathrm{C})$ & 4.6 & $755 \mathrm{~KB}$ & 20 \\
\hline Mengedit Hasil Survei & $34 \%(\mathrm{~F})$ & $77 \%(\mathrm{C})$ & 3.6 & $657 \mathrm{~KB}$ & 19 \\
\hline Menambah Data Warnet & $34 \%(\mathrm{~F})$ & $77 \%(\mathrm{C})$ & 3.4 & $748 \mathrm{~KB}$ & 20 \\
\hline Mengubah Data Warnet & $34 \%(F)$ & $77 \%(\mathrm{C})$ & 3.4 & $749 \mathrm{~KB}$ & 20 \\
\hline Menambah Terbitan Rekomendasi & $36 \%(\mathrm{~F})$ & $77 \%(\mathrm{C})$ & 3.6 & $754 \mathrm{~KB}$ & 20 \\
\hline Mencetak Terbitan Rekomendasi & $28 \%(\mathrm{~F})$ & $77 \%(\mathrm{C})$ & 2.8 & $588 \mathrm{~KB}$ & 16 \\
\hline Mengubah Terbitan Rekomendasi & $34 \%(\mathrm{~F})$ & $77 \%(\mathrm{C})$ & 3.3 & $749 \mathrm{~KB}$ & 20 \\
\hline Mengajukan Pencabutan Izin Warnet & \multicolumn{2}{|c|}{$35 \%(\mathrm{~F})$} & (C) & $748 \mathrm{~KB}$ & 20 \\
\hline Melaporkan Warnet Tercabut & $34 \%(\mathrm{~F})$ & $77 \%(\mathrm{C})$ & 3.1 & $657 \mathrm{~KB}$ & 19 \\
\hline Menambah Pengguna & $34 \%(\mathrm{~F})$ & $77 \%(\mathrm{C})$ & 3.0 & $748 \mathrm{~KB}$ & 20 \\
\hline Mengubah Pengguna & $36 \%(\mathrm{~F})$ & $77 \%(\mathrm{C})$ & 3.8 & $659 \mathrm{~KB}$ & 23 \\
\hline Mencari Pelaporan Warnet & $44 \%(\mathrm{E})$ & $77 \%(\mathrm{C})$ & 1.8 & $361 \mathrm{~KB}$ & 16 \\
\hline Mencetak Pelaporan Warnet & $44 \%(\mathrm{E})$ & $77 \%(\mathrm{C})$ & 1.8 & $361 \mathrm{~KB}$ & 16 \\
\hline Menampilkan Peta & $51 \%$ & $77 \%(\mathrm{C})$ & 2.4 & $731 \mathrm{~KB}$ & 23 \\
\hline
\end{tabular}


Hasil pengujian menunjukkan halaman fungsional yang memiliki performa tertinggi berdasarkan Page Speed Score adalah halaman fungsional Melihat Status Ajuan dengan grade A. Halaman fungsional yang memiliki performa terendah adalah halaman fungsioal Mencetak Terbitan Rekomendasi. Sedangkan rata-rata nilai performa dari semua halaman fungsional adalah sekitar 40\% dengan grade yang dimiliki adalah E untuk pengujian Page Speed Score. Kemudian untuk YSlow, hasil pengujian rata-rata sekitar $78 \%$, dengan grade yang dimiliki adalah $\mathrm{C}$.

\section{Simpulan}

Berdasarkan Hasil dan Pembahasan, dapat disimpulkan bahwa :

a. Untuk membuat sistem informasi manajamen warnet dibutuhkan banyak fungsional dimana terbagi menjadi 4 fungsional utama yaitu : Perekomendasian Warnet, Pencabutan Izin Warnet, Mengelola Pengguna, dan Pelaporan Warnet.

b. Untuk membuat sistem informasi manajamen warnet dengan konsep procedural harus membuat Context diagram, DFD, dan ERD

c. Dengan menggunakan metode blackbox, sistem memiliki tingkat kesuksesan (fungsional yang diterima) dengan kisara 98\%, dan tidak suskes sekitar $2 \%$. Sedangkan pengujian menggunakan GT Metrix menunjukkan rata-rata performa Page Speed Score sekitar $40 \%$ dan YSlow sekitar $78 \%$.

\section{Daftar Pustaka}

[1] Al Fatta, Hanif. 2009. Analisis \& Perancangan Sistem Informasi: Untuk Keunggulan Bersaing Perusahaan dan Organisasi Modern. Yogyakarta : Penerbit Andi.

[2] Bin Ladjamudin, Al Bahra . 2005. Analisis dan Desain Sistem Informasi. Yogyakarta : Graha Ilmu.

[3] C. D. Aprida and F. Samopa. Pembuatan Sistem Informasi Beasiswa Internal Direktorat Jenderal Perbendaharaan Menggunakan PHP dan MySQL, no. Desember 2015, pp. 1-5.2013.

[4] Dhoni. 2011. Dinas Perhubungan, Komunikasi dan Informatika. http://www.karanganyarkab.go.id/20110105/dinasperhubungan-komunikasi-dan-informatika/ . Diakses pada hari Kamis, 17 September 2015.

[5] Faya M. and Fiftin N. Pemanfaatan Google Maps API untuk Pembangunan Sistem Informasi Manajemen Bantuan Logistik Pasca Bencana Alama Berbasis Mobile Web (Studi Kasus : Badan Peannggulangan Bencana Daerah Kota Yogyakarta), no. Desember 2015, pp. 1-10, 2013.

[6] GTMetrix, Canada. https://gtmetrix.com. Diakses pada tanggal 15 Desember 2015.

[7] Liu, Ling. 2009. Encyclopedia of Database Systems. New York : Springer.

[8] Pressman, R.S. 2001. Software Engineering : A practitioner's Approach, $5^{\text {th }}$ Edition. McGraw Hill.

[9] Robby, O. Kwanentent, F. M. Wardana. Analisis dan Perancangan Basis Data untuk Mendukung Aplikasi ERP Education pada Bina Nusantara University (Studi Kasus : Academic Management and Content Preparation), no Desember 2015, pp. $1-12,2009$.

[10] Septyana, Nanda. 2011. Sistem Informasi Kepegawaian Pada Dinas Perhubungan Komunikasi dan Informatika Kabupaten Cilacap. http://dinhubkominfo.jatengprov.go.id/?p=972. Diakses pada hari Sabtu, 19 September 2015. 